\title{
The role of "costs" in political choice: a review
}

\author{
James M. Buchanan and Gordon Tullock, The Calculus of Consent
}

\section{S. SIDNEY ULMER}

Department of Political Science, Michigan State University

It may be accepted that the perceptual framework through which a social scientist views his data is, in part, a product of his professional training. Thus, it is not surprising that political scientists have some difficulty in viewing political decision-making in the same light as other social choice (Long, 1958). Yet, building on the work of such theorists as Luce (1959) and Arrow (1951), some social scientists have boldly taken that step. This is manifested in Anthony Downs' An Economic Theory of Democracy (1957); Thomas Schelling's The Strategy of Conflict (1960); William Riker's Theory of Political Coalitions (1962); Duncan Black's The Theory of Committees and Elections (1958); and now in The Calculus of Consent by James Buchanan and Gordon Tullock (1962). These and other efforts to lift political theory out of the abyss of diffused speculation in which it has labored so long are most welcome.

In The Calculus of Consent the unit of analysis is, as with most "choice" theory, the individual and his rational choice among transitively ranked alternatives. Since individual decisions, when combined, determine collective action, the authors construct a theory to explain the means by which conflict may be reconciled. In this they lean heavily on theoretical work in welfare eco- nomics, the analogy between political and economic choice being maintained throughout the book.

To support such an analogy, two propositions are rejected: (1) that the decisionmaking process is a means of arriving at an absolute truth which will attract all men to its support; and (2) that once the electorate becomes fully informed, individual conflicts will vanish. The "truth" which the individual seeks in that conception is the public interest. This contrasts with the utility maximizer encountered in market theory who, when confronted with alternatives, will choose to maximize self-interest in making his choices. The assumptions of market theory and public interest theory may both be valid if the individual shifts psychological gears as he moves between private and social realms. That such shifting does not generally occur is basic to the authors' argument. Indeed, the theory put forth is that private economic decisions and the choice the individual makes in contributing to collective (political) action are both motivated by the individual's utility function.

We have in The Calculus ... then, the three essential concepts of decision theory: A limited set of alternatives from among which a choice must be made; an individual 
who must make a choice; and a system of subjective preferences by which the individual ranks alternatives, always choosing, if rational, that which is highest in his value scheme. With these concepts, the authors construct a "cost minimization" (C.M.) model in which the maximization of individual utility is defined as the reduction of the cost of social interdependence to zero. These costs are composed of two elements: external costs-those the individual expects to endure as a result of the actions of others over which he has no control, and decision-making costs-those resulting from the participation of the individual in collective or organized activity. Rational behavior of the individual is defined as the maximization of individual utility.

This model is then applied to hypothetical choice situations as reflected in such questions as "When will a society composed of free and rational utility-maximizing individuals choose to undertake action collectively rather than privately?" or, more specifically, "When will an individual member of the group find it advantageous to enter into a 'political' relationship with his fellows?" In the C.M. model, he will do so when he expects to increase his utility by reducing his costs, but ultimate choice in the C.M. model must depend on the relationships between external and decisionmaking costs or on relative costs. These, in turn, depend on the rules which govern decision-making. Thus, in the final analysis, rational behavior can be determined only after ascertaining the effect of various decision-making rules on relative costs. Such consideration takes up a major portion of the book.

As May Brodbeck has pointed out, the term "model" has a halo effect in recent social science literature (1959, p. 373). Consequently, it is not amiss to keep in mind that a theoretical framework such as that developed by Buchanan and Tullock must be evaluated in terms of the function it is designed to serve. That function is to aid in the explanation of observed phenomena. However, though analysis be perfect and conclusions logically drawn, the gap between theory and behavior can be closed only if the assumptions of the theory or model are realistic.

To evaluate the realism of a model, we must be clear as to its assumptions. Although it may be argued that a theory is to be tested by its observable consequences only, whether resources will be invested in such tests will be influenced by the extent to which the theory is considered realistic. Like those rational men who inhabit the models of the decision theorists, the theorist himself, in constructing a model, must choose among the alternative assumptions available to him. It is not clear whether the choices made are subject to explanation by the theory to which they contribute, but it is clear that certain common choice situations face those involved in developing a decision theory. Some of these alternatives and the choices Buchanan and Tullock make among them may be illustrated through the following questions:

\section{Is the rational behavior to which the theory refers descriptive or normative?}

A cardinal notion in utility theory is that, when faced with alternatives, a person chooses optimally relative to his utility function. By such a statement we may mean that the individual should choose in a particular way depending on the constraints imposed by the situation. Or we may intend a description of the way individuals actually choose. Since the C.M. model incorporates the former but not the latter, it follows that the extent to which individual choices are in fact rational, as defined by the C.M. 
model, remains an open question. Moreover, the assumption of consistency made in The Calculus ... runs contrary to empirical data which has led Duncan Luce to suggest that the phenomenon of inconsistency may be basic to the choice process (1962, p. 148).

2. Is the model applicable to all situations in which choice must be made among alternatives?

Here an assumption must be made about the nature of preferences. It may be thought that where there are alternatives there are preferences. Yet, if a person is asked to choose from a series of objects that which fits a particular "real" definition, individual preference would not seem to enter into the calculations. ${ }^{1}$ For a rose is a rose although one might like gardenias better. In all fairness, the B-T paradigm does allow for the possibility of indifference among alternatives, but as to the action to take in such cases, other than a vote against change, the authors' position is unclear to me.

\section{Who is to measure utility?}

In answer to this question, it is possible to say, with the Pareto Optimalists, that only the individual can measure his own utility. Or with the Ordinalist school, one might say that the utility of an alternative is the strength of a preference for it, such preference being discoverable only through observation of choice. Other possibilities would include measures based on difficulty of choice as inferred from the time and other resources devoted to it, or on notions of expected utility. The authors of The Calculus . . . assume that the determination of expected utility (minimization of net cost) is individually made, and the measure of the cost components which

${ }^{1}$ As opposed to a "nominal" definition. This distinction is developed by Robert Bierstedt (1959, pp. 121-44). produce the minimum is a matter for individual judgment. However, they introduce certain limitations on individual autonomy, possibly to avoid a wholly tautological definition of rational behavior.

The point may be illustrated with the authors' analysis of representative government, a schema in which rational behavior is determined by the relationships of four key variables: degree of representation, basis of representation, rules for choosing representatives, and decision-making rules which prevail in the chosen body. The subjective measure of utility is the individual's determination of that particular combination of these variables he finds most satisfying. Thus, one individual may prefer $2 X$, $4 Y, 8 Z$, and $7 W$. Another may find $6 X$, $8 Y, 4 Z$, and $2 W$ most satisfying. The authors, however, introduce an objective element by developing certain cost functions. Throughout The Calculus . . ., decision-making costs are said to rise with the size of the majority required for decision. Conversely, external costs are said to decrease as these quantities increase. In analyzing representative government, similar statements are added for changes in the numerical distribution of preferences in the population (basis of representation) and for degree of representation. Thus, once an individual has established a maximizing equilibrium, the authors are able to prescribe the direction of rational behavior given a change in the magnitude of any one of the four variables. While this reviewer is not inclined to dispute the importance of certain numerical relationships for decisionmaking, the relational assumptions the authors make might be fruitfully examined for their implications.

One example must suffice. In discussing the degree of representation, it is said that "surely the individual will recognize that his own interests will be represented more 
adequately and more faithfully the more closely the representation approaches the full membership of the group" (p. 215). This statement contains two assertions. Assuming the individual will recognize the relationship if it exists, however, we might still ask what conditions are necessary (though not sufficient) for such a relationship. Although a longer list of conditions might be compiled, two may be mentioned. First, given simple majority election, the way in which an increase in the proportionate size of a legislature will relate to representation of minority interests will depend upon the distribution of those interests in the population. The relationship would not hold for a small isolated minority interest until something close to unanimity is approached. It is also assumed that the individual's cost function is a continuous variable. In the $\mathrm{B}-\mathrm{T}$ analysis, the relationship is represented by a nonlinear curve reflecting the law of diminishing marginal utility. While such a curve may sufficiently describe the general relationship, the possibility of discontinuity in the cost function might warrant consideration. Insofar as structural change is to be measured by behavioral consequences, the threshold of response would seem a relevant theoretical datum.

\section{What are the conditions under which decision-making takes place?}

In deciding among alternatives in such a way as to maximize utility, the individual must think primarily in terms of the consequences which his decisional act will produce or promote. The consequences may be certain or uncertain. In market theory, the certainty assumption has been found useful even though some uncertainties are inherent in economic exchange. The same assumption is made in the B-T model, the application of which is to political, not market choice. The authors recognize that political outcome cannot be known with certainty at point of individual decision, but they emphasize that their analysis applies to the plurality of collective decisions over time. Thus, if logrolling is permitted, uncertainty can be reduced if not eliminated. The difficulties with this assumption are several. In the first place, logrolling may not occur. Moreover the fact that $X$ and $Y$ decide to exchange votes on a series of issues is not sufficient in itself to enable prediction of collective outcome with any appreciable degree of certainty. Some improvement may be admitted. The crucial ingredient, however, is knowledge of the exchanges taking place in the group rather than the exchange itself.

The above remarks do not reach the theoretical problems associated with decision-making under risky conditions. If minimization of expected costs determines which alternative an individual will choose, then the individual must be able to predict cost consequences of any choice he makes. For example, if I buy a can of beans, the consequences of my expenditure are (1) immediate and (2) predictable. If I spend my money, I am assured of the beans. Assume, on the other hand, that I vote to shift medical care from the private to the public sector and that I know the decisionmaking rules as well as the decisions that will be made. There is still the problem of estimating the cost, for the individual, of any decision made. This estimate in the B-T model, if I am rational, must control my decision. Yet, in exchange for my vote, I may or may not get the estimated benefit. The possibility of intervening variables must be considered. I may, for example, prefer the private sector if my medical bills are going to be negligible, the public sector otherwise. An estimate of the consequential cost of a shift must involve an estimate of my future medical needs. It is obvious that such an estimate may be in error. Yet in the 
B-T model, the "rationality" of a decision to impose medical costs on the collectivity would not be affected by estimate error. For "rationality" is determined ultimately by the individual's own cost judgments.

Reduction of uncertainty through knowledge of the probabilities attached to the intervening event would not eliminate the theoretical problems. Assume that I know the cost of medical care purchased privately will be $\$ 300$ per year with probability 0.3 and $\$ 100$ with probability 0.7 , all depending on the state of my health. If the cost of public medical care is $\$ 200$ per year with probability 1 (that is, state of health is not a variable), then the question is whether $I$ prefer the chance of a $\$ 100$ cost as against a cost of $\$ 200$ sufficiently to risk a cost of $\$ 300$. The B-T model furnishes little, if any, guidance for this type of situation. Indeed, the choice of the certainty assumption for a decisional model may tend to limit its use to trivial decision situations, for in politics, it is uncertainty that makes the game possible. Generally speaking, those who have attempted to apply economic models in political analysis have assumed too hastily that the explicit and implicit assumptions of economic behavior can be carried over to political behavior. The extent to which this can be done with each and every such assumption is a matter to be determined by testable, empirical consequences, but the literature of political science should furnish some basis for initial judgment.

Having suggested some considerations that might be relevant in evaluating the realism of the B-T model, we may turn to a different kind of inquiry, i.e., does the theory lead to propositions of interest for political activity? The answer here must be strongly in the affirmative in view of the authors' telling theoretical arguments for and against certain prevailing notions in the literature of political science.
The authors' discussion of "intensity" among political preferences is particularly suggestive. By permitting logrolling and similar devices of exchange or side payment, the B-T model mitigates the "equal intensity" assumption of simple majority rule. Moreover, it detracts from the view of some theorists that the bicameral legislature is a structure which enhances the ability of intense minorities to thwart the will of the majority. Buchanan and Tullock show, theoretically, that with diverse bases of representation the bicameral legislature not only reduces external costs but that it automatically distinguishes equal and unequal-intensity measures "imposing much greater restraints on the erection of coalitions by members of intense minorities than on majorities in equal intensity cases" (p. 244). This may be of some interest to those presently pondering the problems of representation associated with the many legislative reapportionment cases now in the courts.

Similarly unexpected views are taken with respect to qualified majorities. Given any collective choice rule, Buchanan and Tullock aver that decision-making costs will be greater in communities characterized by heterogeneous populations than in those in which the population is homogeneous. Suspicion and uncertainty about those who differ in external characteristics will promote bargaining difficulty. By implication, the heterogeneous community should adopt more inclusive rules, i.e., require more than a simple majority for decision. Likewise, as the institutional structure is varied from specific to general decisionmaking, it is rational to support less inclusive rules. When combined, these propositions suggest that the greater the heterogeneity of the population, the greater the activity that should be left to private choice. This relationship is interesting because it 
runs counter to what can be observed among the American states.

Finally, the authors argue that qualified majority rule is not equivalent to minority rule in situations in which neither the majority nor minority preference is adopted. Thus, they see a basic distinction between a positive decision authorizing action and a negative decision blocking action. The latter, they urge, does not constitute effective rule. Since in the B-T model an increase in the required majority decreases external cost, a rational man may well prefer a qualified to a simple majority.

Given the restrictions within which the discussion is conducted, the position taken is clearly tenable. However, certain normative and objective considerations which seem to exist in the real world are rejected or inadequately treated, namely: (1) that in decisional conflict the greater number should prevail and (2) that inaction, in fact, often has the effect of allocating values. The authors' own example can be used to illustrate the latter point. If twothirds of a group is required to impose taxes for road repair, then two-thirds of the members can impose costs on the other one-third. If one-third plus one can block additional taxes, then, it is argued, in no way can such a group impose additional costs on the other two-thirds. But this clearly gives inadequate attention to the fact that real world costs can be imposed on the two-thirds majority by external or third party events. Such costs might be prevented by the majority unless blocked by the minority. In the event of blockage, it would seem fatuous to say that the minority has not imposed a cost. Thus, where (2) prevails the distinction offered between the power to impose a cost and the power to prevent an imposition seems academic.

In sum, nothing said in this review is intended to suggest that The Calculus of
Consent is other than a closely reasoned and major contribution to systematic political theory. Its limitations are basically of the type that afflict all oversimplified theories. As the authors stress, however, this limitation is a challenge to broaden the theory through the lessons to be learned with less complex models. If in the final analysis a theory is to be tested by its observable consequences, the ultimate magnitude of the authors' contribution remains to be determined.

\section{REFERENCES}

Arrow, Kennetr. Social Choice and Individual Values. New York: Wiley \& Sons, 1951.

Bierstedt, Robert. "Nominal and Real Definitions in Sociological Theory." In LLEweLLYN GRoss (ed.), Symposium on Sociological Theory. Evanston, Ill.: Row, Peterson, 1959.

Black, Duncan. The Theory of Committees and Elections. Cambridge, England: University Press, 1958.

Brodbeck, May. "Models, Meaning and Theories." In Gross, op. cit.

Buchanan, James M. and Tullock, Gordon. The Calculus of Consent. Ann Arbor, Mich.: The University of Michigan Press, 1962.

Downs, ANTHONy. An Economic Theory of Democracy. New York: Harper \& Bros., 1957.

Long, Norton. "The Local Community as an Ecology of Games," American Journal of Sociology, 44 (November 1958), 251.

LuCE, R. DunCan. Individual Choice Behavior. New York: Wiley \& Sons, 1959.

- "Psychological Studies of Risky Decision-Making." In GeORGE B. Strother (ed.), Social Science Approaches to Business Behavior. Homewood, Ill.: Dorsey Press, 1962.

Luce, R. Duncan and Raiffa, H. Games and Decisions. New York: Wiley \& Sons, 1957.

Riker, William. Theory of Political Coalitions. New Haven, Conn.: Yale University Press, 1962.

Schelling, Thomas C. The Strategy of Conflict. Cambridge, Mass.: Harvard University Press, 1960. 